\title{
Effect of Seeding Density on Mat-Type Seedling Quality for Mechanical Transplanting in Dry Season Rice
}

\author{
Nilufar Yasmin Shaikh"1, Md. Ashraful Alam², Mohammad Kamruzzaman ${ }^{2 *}$, \\ Md. Abdullah Al Mamun ${ }^{3}$, AKM Saiful Islam² \\ ${ }^{1}$ Biotechnology Division, Bangladesh Rice Research Institute (BRRI), Gazipur, Bangladesh \\ ${ }^{2}$ Farm Machinery and Post-Harvest Technology Division, Bangladesh Rice Research Institute (BRRI), Gazipur, Bangladesh \\ ${ }^{3}$ Agricultural Statistics Division, Bangladesh Rice Research Institute (BRRI), Gazipur, Bangladesh \\ Email: biithiii@gmail.com, ashraf1982s@gmail.com, *milonbrri@gmail.com, amunru4777@gmail.com, \\ akmsaiful68@yahoo.com
}

How to cite this paper: Shaikh, N.Y., Alam, Md.A., Kamruzzaman, M., Al Mamun, Md.A. and Islam, AKMS. (2021) Effect of Seeding Density on Mat-Type Seedling Quality for Mechanical Transplanting in Dry Season Rice. Agricultural Sciences, 12, 1231-1243.

https://doi.org/10.4236/as.2021.1211078

Received: September 19, 2021

Accepted: November 7, 2021

Published: November 10, 2021

Copyright $\odot 2021$ by author(s) and Scientific Research Publishing Inc. This work is licensed under the Creative Commons Attribution International License (CC BY 4.0).

http://creativecommons.org/licenses/by/4.0/ (c) (i) Open Access

\begin{abstract}
Rice transplanting with a transplanter is a cost-effective process. Due to labor shortages during the peak time of rice transplanting, it is a promising technology in Bangladesh. However, the high-quality mat-type seedling is a prerequisite factor for mechanical transplanting. The experiments were conducted at three different locations (Gazipur, Tangail, and Rangpur) during the dry season (Boro)/2019-20 to determine the best seeding density for high-quality mat-type seedlings to be prepared for mechanical rice transplanters. The effects of seeding rate on seedling quality such as survival rate, seedling strength, stem thickness of newly released boro rice varieties BRRI dhan86, BRRI dhan89, and BRRI dhan92 were studied using four seeding rates $(130,140,150,160 \mathrm{~g} /$ tray). Results revealed that BRRI dhan92 showed quick seedling emergence compared to BRRI dhan 89 and BRRI dhan 86 . Seedling mortality was found the lowest BRRI dhan92 while the highest in BRRI dhan86. 25 - 30 days old seedling was found suitable for mechanical transplanting in terms of seedling mortality. Seedling height increased with the increase in seed density. BRRI dhan92 showed the highest stem thickness followed by BRRI dhan 89 and BRRI dhan 86 with seed rate $150-160 \mathrm{~g}$ per tray. The suitable seeding rate $(150-160 \mathrm{~g} /$ tray) for the studied varieties was found better for raising mat-type seedlings suitable for mechanical transplanting, which could coordinate the production of larger population growth and higher harvest index to achieve high grain yield.
\end{abstract}

\section{Keywords}

Rice, Seed Density, Mortality, Seedling Age, Stem Thickness, Seedling Strength 


\section{Introduction}

Rice (Oryza sativa L.) is one of the most important cereal crops in Bangladesh and the country's most important staple food. The two most popular methods of rice establishment are direct seeding and transplanting [1]. When compared to direct-seeded rice, farmers prefer the transplanting method because it produces higher yields and has less weed growth. However, it does necessitate a significant amount of time and effort [2].

In Bangladesh, rice is transplanted either manually or mechanically. Farmers in this country commonly transplant wash root rice seedlings by hand. This process required more manual labor and time than mechanical transplantation. Manjunatha et al. [3] found that the mechanical transplanter performed satisfactorily, requiring just three-man days per hectare compared to 33-man days per hectare for manual transplanting. Paddy transplanting by hand took around 238-manh per hectare [4]. Moreover, farmers do not consider hill to hill distance and maintain the plant population properly in manual. Mechanical transplanting has the advantages of ensuring timely transplantation, saving time and labor, minimizing costs, uniform spacing of plants and optimum plant density with 2 3 seedling per hill and less movement shock of seedlings, early seedling vigor, and uniform crop stand [3] [5]. Transplant infant seedlings by mechanical rice transplanter produced 9\% - 14\% more yield than traditional manual transplanting in BRRI dhan 28 during Boro season [6]. Considering the above facts, policymakers are being forced to make a paradigm shift toward increased use of mechanical operations in rice farming. However, raising quality mat-style nurseries in frames or fields is a time-consuming and labor-intensive precise technique that could be one of the biggest barriers to mechanical transplantation adoption.

Raising mat-type nurseries in frames or fields using polythene sheets necessitates a great deal of labor and attention before transplanting is completed. The transplanter's output will be harmed if the plant population in the nursery is unequal. The nursery mat characteristics (mat thickness, seedlings per square meter, seedling age, base material) must be optimized based on soil type to improve the transplanter's efficiency. Cultivation techniques, nursery management, types of variety and seeding density influence the efficiency of machine transplanting [7] [8] [9]. The seeding density of mat-type nursery influences the seedling quality, plant establishment, and the percentage of missing hills during transplanting. However, seedling quality and limitation of seeding density reduce the efficiency of mechanical transplanting [10] [11] [12]. Poor quality of seedlings, high seeding density, high rate of seedlings injury, and a large number of seedlings per hill cannot achieve the advantage of high yielding variety [13] [14] [15]. Therefore, uniform seed distribution on the tray, uniform size of seedling, consistent growth, and good seedling characteristics are necessary to make suitable seedlings for different types of rice variety in mechanical transplanting. Previous studies have shown that uniform seedlings emergence was observed in high seeding density compared to the low seeding density. However, 
seedling quality decreases with the increase of seeding density, root-shoot dry weight, and root vigor exhibited a decreasing trend with the increase of seeding density [9]. Besides, excessive seed density increases mortality although the sum of seedlings in each tray was increased [5]. Hossen et al. [16] examined the seeding rates in three rice varieties: BR3 (short and bold grain), BRRI dhan 28 (medium and slender grain), and BRRI dhan 50 (extra-long and slender grain). They discovered that using $140 \mathrm{~g}$ of seeds.tray ${ }^{-1}$ for BR3, $130 \mathrm{~g}$ of seeds.tray ${ }^{-1}$ for BRRI dhan28, and $120 \mathrm{~g}$ of seeds.tray ${ }^{-1}$ for BRRI dhan50 can achieve desired seedlings per hill and minimal missing hills while maintaining good quality. Thus, seeding density is one of the most significant constraints to produce good quality rice seedlings in a plastic tray which is linked to the characteristics of rice varieties [7]. However, only a few studies have been conducted in the past to determine the optimal seed rate for quality seedling production to reduce the percentage of missing hills. Therefore, it is of utmost needed to optimize the seeding density in different newly developed popular varieties of rice for quality mat-type seedlings production.

In light of the above, the current study was conducted to determine the impact of seed density on seedling quality in dry-season rice (Boro season). This research will be useful in determining the suitability of the most recent varieties and seed densities for providing quality seedlings and reducing null hills.

\section{Material and Methods}

\subsection{Plant Materials and Experimental Design}

The experiments were conducted in the irrigated dry season (Boro) at three different locations i.e. Gazipur, Rangpur, and Tangail. The 2-factors experiment was carried out following the Randomized Complete Block Design (RCBD) with three replications. Newly released boro rice varieties, BRRI dhan86 (V1), BRRI dhan89 (V2), and BRRI dhan92 (V3) were used in these experiments as main factors. Four different seed density $130 \mathrm{~g}$ (SR1), $140 \mathrm{~g}$ (SR2), $150 \mathrm{~g}$ (SR3), and $160 \mathrm{~g}$ (SR4) were used as a sub-factor for growing on the tray. Sprouting seeds were sown on the $8^{\text {th }}$ of December in Gazipur, the $10^{\text {th }}$ in Rangpur, and the $6^{\text {th }}$ in Tangail.

\subsection{Seedling Preparation and Management}

Sun-dried seeds were cleaned to remove impurities and immersed into the water before incubation to remove unfilled grain and other impurities. To protect seedlings from seed-borne diseases Atostin (i.e. Carbendazim) powder mixed water treat was used. Seed germination percentage was checked (>95\%). Healthy seeds were picked by a specific gravity method. The pre-soaked seeds were weighed according to treatment, soaked in water overnight before sowing, and the partially sprouted seedling trays were put in the wet nursery two days after incubation. The native soil was collected in the field and sieved to extract stones, dirt, and weed seeds using a $2 \mathrm{~mm}$ mesh sieve. Water was supplied regularly considering soil condition. The trays were open from $8 \mathrm{AM}$ to $5 \mathrm{PM}$ and the rest 
of the time covered by a transparent polythene sheet to retain solar radiation and helped to increase the inside air temperature during a cold spell.

\subsection{Data Collection}

The agronomic characteristics of seedling emergence per unit area, seedling height, number of leaves, leaf length (Only the $1^{\text {st }}$ leaf length was measured under this study), and stem length were counted every five days (5 to 30 days) after seeds spreading on the trays. The metal box having 400 square $\mathrm{mm}$ area was placed in three places in each tray to determine the seedling emergence, seedling mortality, and seedling density. Vernier caliper was used to measure stem thickness of 30 days old seedling. The shoot length was measured from the base to the tip of the topmost leaf and expressed in millimeters after ten seedlings were randomly selected by hand from each treatment combination. The roots were separated from the shoot using scissors. Collected roots and shoots were dried in a hot air circulating oven at $70^{\circ} \mathrm{C}$ for $72 \mathrm{~h}$. Seedling strength was measured dry weight of shoots in $\mathrm{mg}$ to the length of shoots per $10 \mathrm{~mm}$. Dry matter of roots and shoots of seedlings was measured by using the precision balance in milligrams. The ratio of the root-shoot length of seedlings was also calculated from oven-dried samples. Day and night air temperatures have been recorded in all locations. The temperature of the three study locations was presented in Figure 1. Temperatures inside and outside of the polythene cover were recorded six times per day and night.
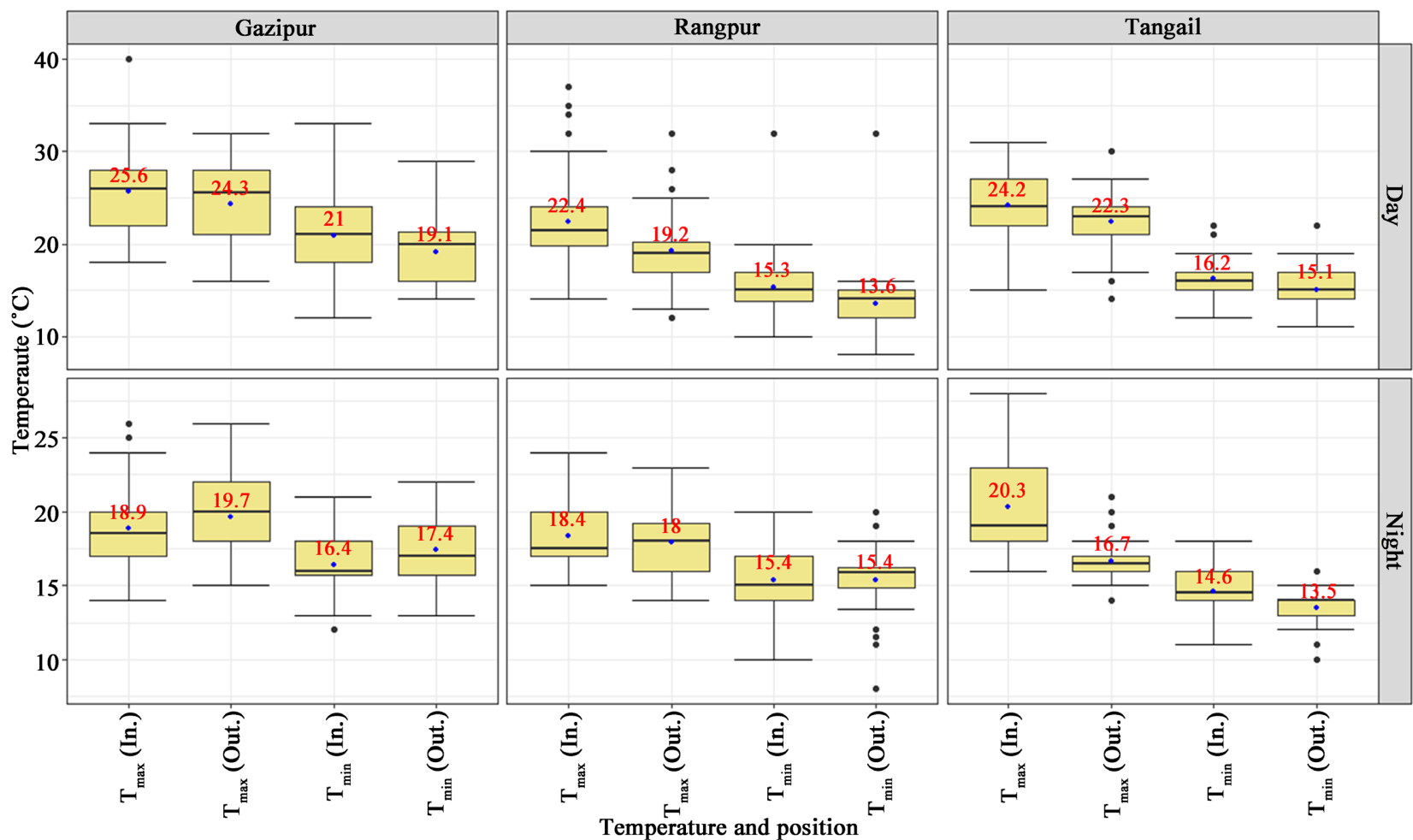

Figure 1. The temperature profile of the study areas during the study period. 


\subsection{Data Analysis}

Data were organized and formatted in MS Excel software (MS Office 2013). ANOVA and mean comparison were done following Gomez and Gomez [17] utilizing Crop Stat 7.2 software [18]. The least significant difference (LSD) test was used to compare the means using the Statistix 10 program (Statistix 10 software, 2013).

\section{Results}

\subsection{Seedling Emergence}

Table 1 showed the influence of seed density and variety on seedling emergence (\%) in three different locations. According to statistical analysis of data, seed rate and variety had a significant impact on seedling emergence (\%), as did seeding and variety interaction. It was found that seedling emergence increased linearly with time up to 25 days after sowing in all rice varieties and seed rates. However, seedling mortality of all varieties started within 25 - 30 days after seeding. Seedling mortality of BRRI dhan 86 was highest in Rangpur and Tangail locations.

According to Table 1, more than 50\% seedling emergence after 5 days in all rice verities as well as seed rates where BRRI dhan92 displayed highest (75\%). Seed density of 150 to $160 \mathrm{~g}$ exhibited the highest number of seedlings emergence in the tray growing seedling. BRRI dhan92 exhibited the highest seedling emergence and seedling survival followed by BRRI dhan 89 and BRRI dhan 86. BRRI dhan86 always showed late and low emergence.

Table 1. Seedling emergence (\%) in BRRI dhan86, BRRI dhan89, and BRRI dhan92 with different seed densities (g/tray) at three different locations.

\begin{tabular}{|c|c|c|c|c|c|c|c|c|c|c|c|c|c|c|c|c|c|c|}
\hline \multirow{3}{*}{ Treatment } & \multicolumn{6}{|c|}{ Gazipur } & \multicolumn{6}{|c|}{ Rangpur } & \multicolumn{6}{|c|}{ Tangail } \\
\hline & \multicolumn{6}{|c|}{ Day after sowing } & \multicolumn{6}{|c|}{ Day after sowing } & \multicolumn{6}{|c|}{ Day after sowing } \\
\hline & 5 & 10 & 15 & 20 & 25 & 30 & 5 & 10 & 15 & 20 & 25 & 30 & 5 & 10 & 15 & 20 & 25 & 30 \\
\hline \multicolumn{19}{|l|}{ Seed rate (per tray) } \\
\hline $130 \mathrm{~g}$ & 68.4 & 76.2 & 80.6 & 81.3 & 81.7 & 68.4 & 71.9 & 73.3 & 75.1 & 76.3 & 76.7 & 75.3 & 26.4 & 52.7 & 68.2 & 74.6 & 74.1 & 71.7 \\
\hline $140 \mathrm{~g}$ & 65.2 & 78.5 & 81.6 & 80.4 & 81.3 & 65.2 & 69.7 & 70.8 & 74.9 & 79.2 & 79.6 & 77.2 & 30.9 & 53.1 & 66.8 & 72.9 & 71.2 & 67.7 \\
\hline $150 \mathrm{~g}$ & 66.7 & 81.2 & 87.4 & 87.4 & 88.9 & 66.7 & 91.3 & 91.5 & 93.1 & 89.2 & 88.7 & 85.4 & 29.1 & 53.2 & 66.1 & 76.3 & 73.3 & 70.0 \\
\hline $160 \mathrm{~g}$ & 67.5 & 81.2 & 86.8 & 86.0 & 86.8 & 67.5 & 65.6 & 66.6 & 74.1 & 75.6 & 77.6 & 76.3 & 29.6 & 48.4 & 61.9 & 69.9 & 67.7 & 64.8 \\
\hline $\mathrm{LSD}_{0.05}$ & NS & 4.1 & 3.2 & 3.7 & 3.4 & 6.1 & 21.3 & 21.1 & 18.5 & 15.1 & NS & NS & 3.7 & 4.2 & 3.4 & 1.9 & 3.3 & 3.3 \\
\hline \multicolumn{19}{|l|}{ Variety } \\
\hline BRRI dhan 86 & 56.6 & 70.4 & 77.5 & 76.6 & 77.9 & 56.6 & 61.9 & 60.8 & 66.8 & 70.4 & 72.5 & 70.9 & 24.2 & 47.4 & 60.0 & 70.2 & 69.1 & 66.2 \\
\hline BRRI dhan89 & 69.2 & 82.1 & 87.7 & 88.0 & 89.2 & 69.2 & 75.6 & 77.1 & 79.8 & 79.5 & 79.9 & 78.3 & 30.1 & 51.9 & 66.2 & 73.6 & 71.2 & 68.2 \\
\hline BRRI dhan92 & 75.0 & 85.4 & 87.0 & 86.7 & 86.9 & 75.0 & 86.4 & 88.7 & 91.4 & 90.3 & 89.6 & 86.8 & 32.7 & 56.2 & 70.9 & 76.4 & 74.4 & 71.2 \\
\hline $\mathrm{LSD}_{0.05}$ & 5.3 & 3.6 & 3.7 & 3.2 & 2.9 & 5.3 & 18.4 & 18.3 & 16.0 & 13.0 & 12.5 & 11.8 & 3.2 & 3.6 & 2.9 & 3.2 & 2.8 & 2.8 \\
\hline Interactions $\mathrm{LSD}_{0.05}$ & 10.6 & 7.1 & $6 . .32$ & 6.4 & 5.9 & 10.6 & 36.9 & 36.6 & 32.0 & 26.1 & 25.0 & 23.6 & 6.3 & 7.2 & 5.9 & 6.4 & 5.7 & 5.7 \\
\hline
\end{tabular}




\subsection{Seedling Height}

Table 2 displayed the seedling height ( $\mathrm{mm}$ ) in BRRI dhan86, BRRI dhan89, and BRRI dhan92 with different seed densities (g/tray) at different three locations. The combined effect of variety and seed rate, as well as the single effect, had a significant effect on seedling height. It was found that the seedling height is increased progressively with time in all the rice varieties. Seed density of 150 to 160 g per tray exhibited the tallest seedling at Gazipur followed by Rangpur and Tangail. Moreover, BRRI dhan92 attained the highest seedling height at 30 DAS followed by BRRI dhan 86 and BRRI dhan 89 .

\subsection{Leaf Number}

Table 3 shows the seedling leaf number in BRRI dhan86, BRRI dhan89, and BRRI dhan92 with different seed densities (g/tray) at different three locations. In terms of seedling leaf number, both the combined and single effects of seed rate and variety were insignificant. In all the rice types, the number of leaves was increased over time. In this study, each variety attained 3 leaves at 20 DAS and 4 to 5 leaves at 25 to 30 DAS.

\subsection{Seedling Stem Thickness}

Stem thickness in BRRI dhan86, BRRI dhan89, and BRRI dhan92 at three different locations with different seed densities (g/tray) are presented in Table 4. The

Table 2. Seedling height ( $\mathrm{mm})$ in BRRI dhan86, BRRI dhan89, and BRRI dhan92 with different seed densities (g/tray) at different three locations.

\begin{tabular}{|c|c|c|c|c|c|c|c|c|c|c|c|c|c|c|c|}
\hline \multirow{3}{*}{ Treatment } & \multicolumn{5}{|c|}{ Gazipur } & \multicolumn{5}{|c|}{ Rangpur } & \multicolumn{5}{|c|}{ Tangail } \\
\hline & \multicolumn{5}{|c|}{ Day after sowing } & \multicolumn{5}{|c|}{ Day after sowing } & \multicolumn{5}{|c|}{ Day after sowing } \\
\hline & 10 & 15 & 20 & 25 & 30 & 10 & 15 & 20 & 25 & 30 & 10 & 15 & 20 & 25 & 30 \\
\hline \multicolumn{16}{|l|}{ Seed rate (per tray) } \\
\hline $130 \mathrm{~g}$ & 30.1 & 53.4 & 65.3 & 76.2 & 87.9 & 41.0 & 56.4 & 71.5 & 77.4 & 85.9 & 24.6 & 37.8 & 50.2 & 63.8 & 75.9 \\
\hline $140 \mathrm{~g}$ & 31.5 & 56.5 & 67.1 & 79.0 & 91.8 & 41.7 & 57.4 & 74.7 & 82.9 & 88.4 & 23.9 & 36.7 & 48.0 & 62.4 & 75.9 \\
\hline $150 \mathrm{~g}$ & 33.2 & 57.5 & 71.8 & 81.5 & 92.4 & 42.2 & 57.6 & 76.7 & 82.8 & 89.4 & 23.3 & 36.7 & 48.8 & 63.2 & 76.4 \\
\hline $160 \mathrm{~g}$ & 33.5 & 59.5 & 70.5 & 81.9 & 93.8 & 40.2 & 54.6 & 72.4 & 80.0 & 88.6 & 22.1 & 36.0 & 47.9 & 62.4 & 74.8 \\
\hline $\mathrm{LSD}_{0.05}$ & 3.1 & 3.8 & 3.5 & 3.6 & 4.2 & NS & 2.2 & 2.3 & 2.6 & 2.9 & 1.1 & 1.2 & 1.5 & 1.8 & 1.8 \\
\hline \multicolumn{16}{|l|}{ Variety } \\
\hline BRRI dhan 86 & 29.0 & 59.0 & 70.3 & 80.9 & 92.9 & 39.3 & 58.1 & 75.7 & 81.9 & 92.5 & 23.2 & 36.1 & 47.9 & 60.2 & 72.6 \\
\hline BRRI dhan 89 & 28.9 & 49.6 & 62.3 & 73.6 & 84.5 & 39.2 & 53.1 & 69.9 & 77.0 & 83.8 & 24.0 & 36.3 & 47.4 & 61.1 & 74.2 \\
\hline BRRI dhan92 & 38.2 & 61.4 & 73.5 & 84.4 & 97.0 & 45.3 & 58.2 & 75.8 & 83.4 & 88.0 & 23.1 & 37.9 & 50.9 & 67.5 & 80.5 \\
\hline $\mathrm{LSD}_{0.05}$ & 2.7 & 3.3 & 3.0 & 3.1 & 3.7 & 2.2 & 1.9 & 2.0 & 2.3 & 2.5 & NS & 1.1 & 1.3 & 1.6 & 1.6 \\
\hline Interactions $\mathrm{LSD}_{0.05}$ & 5.4 & 6.5 & 6.0 & 6.2 & 7.3 & 4.5 & 3.8 & 4.0 & 4.6 & 5.0 & 1.8 & 2.2 & 2.6 & 3.2 & 3.1 \\
\hline
\end{tabular}


Table 3. Number of leaves in BRRI dhan86, BRRI dhan89, and BRRI dhan92 with different seed densities (g/tray) at different three locations.

\begin{tabular}{|c|c|c|c|c|c|c|c|c|c|c|c|c|c|c|c|}
\hline \multirow{3}{*}{ Treatment } & \multicolumn{5}{|c|}{ Gazipur } & \multicolumn{5}{|c|}{ Rangpur } & \multicolumn{5}{|c|}{ Tangail } \\
\hline & \multicolumn{5}{|c|}{ Day after sowing } & \multicolumn{5}{|c|}{ Day after sowing } & \multicolumn{5}{|c|}{ Day after sowing } \\
\hline & 10 & 15 & 20 & 25 & 30 & 10 & 15 & 20 & 25 & 30 & 10 & 15 & 20 & 25 & 30 \\
\hline \multicolumn{16}{|l|}{ Seed rate (per tray) } \\
\hline $130 \mathrm{~g}$ & 1.19 & 2.07 & 2.99 & 4.00 & 5.00 & 1.58 & 2.08 & 2.86 & 4.00 & 5.00 & 1.00 & 2.00 & 3.00 & 4.00 & 5.00 \\
\hline $140 \mathrm{~g}$ & 1.17 & 2.05 & 2.96 & 4.00 & 5.00 & 1.64 & 2.17 & 2.89 & 4.00 & 5.00 & 1.00 & 2.00 & 3.00 & 4.00 & 5.00 \\
\hline $150 \mathrm{~g}$ & 1.14 & 2.03 & 2.97 & 4.00 & 5.00 & 1.53 & 2.22 & 2.92 & 4.00 & 5.00 & 1.00 & 2.00 & 3.00 & 4.00 & 5.00 \\
\hline $160 \mathrm{~g}$ & 1.27 & 2.02 & 2.99 & 4.00 & 5.00 & 1.58 & 2.14 & 2.92 & 4.00 & 5.00 & 1.00 & 2.00 & 3.00 & 4.00 & 5.00 \\
\hline $\operatorname{LSD}_{0.05}$ & 0.05 & 0.03 & NS & NS & NS & NS & NS & NS & NS & NS & NS & NS & NS & NS & NS \\
\hline \multicolumn{16}{|l|}{ Variety } \\
\hline BRRI dhan 86 & 1.25 & 2.11 & 3.00 & 4.00 & 5.00 & 1.54 & 2.13 & 2.90 & 4.00 & 5.00 & 1.20 & 2.00 & 3.00 & 4.00 & 5.00 \\
\hline BRRI dhan89 & 1.11 & 2.00 & 2.94 & 4.00 & 5.00 & 1.58 & 2.08 & 2.85 & 4.00 & 5.00 & 1.40 & 2.00 & 3.00 & 4.00 & 5.00 \\
\hline BRRI dhan92 & 1.22 & 2.02 & 2.99 & 4.00 & 5.00 & 1.63 & 2.25 & 2.94 & 4.00 & 5.00 & 1.10 & 2.00 & 3.00 & 4.00 & 5.00 \\
\hline $\mathrm{LSD}_{0.05}$ & 0.04 & 0.03 & 0.03 & NS & NS & NS & 0.12 & NS & NS & NS & NS & NS & NS & NS & NS \\
\hline Interactions $\mathrm{LSD}_{0.05}$ & 0.08 & 0.06 & 0.05 & NS & NS & NS & 0.14 & NS & NS & NS & NS & NS & NS & NS & NS \\
\hline
\end{tabular}

Table 4. Seedling stem thickness ( $\mathrm{mm}$ ) in BRRI dhan86, BRRI dhan89, and BRRI dhan92 with different seed densities ( $\mathrm{g} /$ tray) at different three locations.

\begin{tabular}{cccc}
\hline Treatment & Gazipur & Rangpur & Tangail \\
\hline Seed rate (per tray) & 1.48 & 1.75 & 1.33 \\
$130 \mathrm{~g}$ & 1.49 & 1.69 & 1.39 \\
$140 \mathrm{~g}$ & 1.44 & 1.64 & 1.38 \\
$150 \mathrm{~g}$ & 1.44 & 1.67 & 1.38 \\
$160 \mathrm{~g}$ & 0.20 & 0.77 & $\mathrm{NS}$ \\
LSD 0.05 & & & \\
Variety & 1.48 & 1.70 & 1.32 \\
BRRI dhan86 & 1.46 & 1.72 & 1.36 \\
BRRI dhan89 & 1.45 & 1.65 & 1.42 \\
BRRI dhan92 & 0.18 & $\mathrm{NS}$ & 0.46 \\
LSD 0.05 & 0.35 & 1.55 & 0.93 \\
\hline Interactions LSD & &
\end{tabular}

thickness of the stem varies according to the variety, seed rate, and location. Variety and seed rate had significant effects on the stem thickness of the raised seedlings. 
According to Table 4, the Rangpur location had the thickest stems, followed by Gazipur and Tangail. The stem thickness of BRRI dhan 89 seedlings was found to be higher than the other two varieties at all seed rates except for Tangail. Irrespective of the seed rate, the highest stem thickness $(1.64-1.75 \mathrm{~mm})$ was observed in Rangpur, followed by Gazipur (1.44 - $1.49 \mathrm{~mm})$. In the Gazipur location, the highest stem thickness $(1.49 \mathrm{~mm})$ was found in the seed rate of 130 and $140 \mathrm{~g}$ followed by a seed rate of 150 and $160 \mathrm{~g}$. The highest stem thickness $(1.75 \mathrm{~mm})$ was found in the seed rate of $130 \mathrm{~g}$ in Rangpur followed by stem thickness $(1.63 \mathrm{~mm})$ in the seed rate of $150 \mathrm{~g}$. However, stem thickness was very low in all seed rates at the Tangail site. Stem thickness decreased as the seed rate increased.

\subsection{Seedling Strength}

The strength of seedlings was measured in milligrams per millimeter squared of shoot dry weight. Table 5 shows the seedling strength in BRRI dhan86, BRRI dhan89, and BRRI dhan92 at three different locations with different seed densities (g/tray). Seedling strength varies according to variety, seed rate, and location. The seedling strength was significantly affected by the variety while insignificant with the seed rate. Seedling strength was strongest in BRRI dhan89, followed by BRRI dhan86 and BRRI dhan92. In the Rangpur locations, the varieties had the stronger seedling strength compared to other regions. Considering the seeding density, $160 \mathrm{~g}$ per tray developed the strongest seedlings.

Table 5. Seedling strength $(\mathrm{mg} / \mathrm{mm})$ in BRRI dhan86, BRRI dhan 89 , and BRRI dhan 92 with different seed densities ( $\mathrm{g} /$ tray) at different three locations.

\begin{tabular}{cccc}
\hline Treatment & Gazipur & Rangpur & Tangail \\
\hline Seed rate (per tray) & & & \\
$130 \mathrm{~g}$ & 1.48 & 1.75 & 1.33 \\
$140 \mathrm{~g}$ & 1.49 & 1.69 & 1.39 \\
$150 \mathrm{~g}$ & 1.44 & 1.64 & 1.38 \\
$160 \mathrm{~g}$ & 1.44 & 1.67 & 1.38 \\
LSD 0.05 & 0.20 & 0.77 & $\mathrm{NS}$ \\
Variety & & & \\
BRRI dhan86 & 1.48 & 1.70 & 1.32 \\
BRRI dhan89 & 1.46 & 1.72 & 1.36 \\
BRRI dhan92 & 1.45 & 1.65 & 1.42 \\
LSD $_{0.05}$ & 0.18 & $\mathrm{NS}$ & 0.46 \\
Interactions LSD & 0.05 & 1.55 & 0.93 \\
\hline
\end{tabular}




\section{Discussions}

Rice yield increase was linked with hill density, the number of effective tillers per hill and the number of spikelets per panicle [19]. However, the effectiveness of a rice transplanter is determined by the quality of the seedlings. Seedling density in the seedling tray influences seedling quality [20]. An optimal seeding density is essential to establish a sufficient plant population [21]. Seedling density on a tray is determined by seed rate, germination percentage, and seedling survival rate [5]. In the present study, seed density of 150 to $160 \mathrm{~g}$ per tray exhibited the highest number of seedlings emergence. Hisashi et al., [22] reported that seed density for tray-type seedlings ought to be 130 to $150 \mathrm{~g}$ per tray to obtain 3 to 5 seedlings per hill. Hossen et al. [16] reported seedling emergence decreased with the increase of seed density from 100 to $160 \mathrm{~g}$ in each tray. They also found that the number of seedlings increased, and the percentage of null hills decreased with the increase of seed density for the rice transplanter which was nearly similar to this study. Moreover, cold tolerance characteristics of a variety at the germination and seed emergence stage are essential to obtain optimum plant population. BRRI dhan92 exhibited the highest seedling emergence and seedling survival followed by BRRI dhan89 and BRRI dhan86. BRRI dhan 86 always showed late and low emergence. It might be due to susceptibility to cold. Cold stress and low temperature affected the seedling mortality in Boro paddy production [23]. In this study, seedling mortality of all varieties started within 25 - 30 days after seeding. Seedling mortality of BRRI dhan 86 was highest in Rangpur and Tangail locations. It might be due to the low-temperature effect in these two locations (Figure 1). Dixit et al. [4] reported that seedlings with 20 to 30 days old were observed most appropriate for mechanical transplanting. Therefore, the mat-type seedlings of BRRI dhan86, BRRI dhan 89 and BRRI dhan92 should be mechanically transplanted within 25 - 30 days.

Furthermore, an appropriate seedling height, number of leaves during transplanting, and stem thickness are also important criteria for quality transplanting, as are suppressed plants under the soil, picker missing, floating hills, and mechanical damage hills. Islam [5] mentioned that seedling height is one of the major criteria in mechanical transplanting and the lowest seedling height increased the buried hill. The author also mentioned that seedling height should be more than $80 \mathrm{~mm}$ in the Boro season. However, other studies reported that 120 to $150 \mathrm{~mm}$ seedling height with 3 leaves stage is suitable for mechanized transplanting [3]. In this study, the seedling height of BRRI dhan92 satisfied the requirement of mechanical transplanting in all locations. BRRI dhan 86 and BRRI dhan 89 could not attain the desirable seedling height (less than $80 \mathrm{~mm}$ ) for mechanical transplanting in the Tangail location. In Tangail, the seedling height of all the variety retarded, it might be due to cold stress. The minimum temperature in Tangail during the study period was less than $15^{\circ} \mathrm{C}$. This low temperature might be influenced the germination rate and vegetative growth of the seedling. Seedling height having less than $80 \mathrm{~mm}$ increased the buried hill during me- 
chanical transplanting. In that situation, care should be taken to prepare land preparation and maintain the depth of mud. On the other hand, the depth of placement should be adjusted in the lowest position in the mechanical transplanter. Seed rate showed a significant effect on seedling height. In this study, seed density of 150 to $160 \mathrm{~g}$ per tray exhibited the tallest seedling at Gazipur followed by Rangpur and Tangail. Our study suggested that seed rate showed a significant effect on seedling height. However, Hossen et al. [16] found that the 130 g seed rate gave the highest seedling height $(112 \mathrm{~mm})$. It may be depending on variety and location as well.

Leaf number is another factor indicating the physiological age of seedlings to transplant in the field. Rice variety and seed density discovered an insignificant impact on the leaf number of seedlings. The number of leaves and number of tillers has been not considerably stimulated with the aid of using distinct seeding density [23]. In this study, each variety attained 3 leaves at 20 DAS and 4 to 5 leaves at 25 to 30 DAS. Poornima et al. [24] recommended that seedlings having 4 to 5 leaves suitable for mechanical transplanting to the field.

Stem thickness is an important trait of seedlings in mechanical transplanting. Stem thickness regulated the number of seedlings dispensed in each stroke. Thick stem reduced the number of seedlings dispensed in each stroke. However, the picker can shred the skinny stem during picking. BRRI dhan86 showed the highest stem thickness $(1.50 \mathrm{~mm})$ in the Gazipur location followed by BRRI dhan89 $(1.50 \mathrm{~mm})$. BRRI dhan89 showed the highest stem thickness $(1.72 \mathrm{~mm})$ in Rangpur followed by BRRI dhan $86(1.70 \mathrm{~mm})$. BRRI dhan92 exhibited the highest stem thickness $(1.42 \mathrm{~mm})$ in the Tangail location followed by BRRI dhan89 $(1.36 \mathrm{~mm})$. BRRI dhan89 showed the highest stem thickness among all the locations. Every variety exhibited the highest stem thickness of $1.60-1.70$ $\mathrm{mm}$ in the Rangpur location followed by $1.40-1.50 \mathrm{~mm}$ in the Gazipur location. Shahed et al. [25] reported that stem thickness and strength varied with seedling growing media, soil fertility, ambient temperature, etc. The study revealed that stem thickness decreased as the seed rate increased. This statement coincides with the findings of Hossen et al. [16]. They observed that BRRI dhan28 with 100 and 120 g per tray seed density contributed considerably better stem thickness over different varieties and seed density. Variety having high seedling strength can protect seedling damage during picking the seedlings in mechanical transplanting. The variety had a significant impact on seedling strength, while seed rate did not affect. BRRI dhan89 had the highest seedling strength, followed by BRRI dhan 86 and BRRI dhan92. In comparison to other regions, the varieties in Rangpur had the strongest seedling strength due to soil fertility, ambient temperature.

\section{Conclusion}

Seedling emergence, seedling age, height, leaf number, seedling stem thickness, and seedling strength are all important factors to be considered when using a 
rice transplanter on a large scale. The seedling quality is varied with variety, seed rate, and locations. BRRI dhan 92 and BRRI dhan 89 are more suitable for machine transplanting in the Boro season under 150 to $160 \mathrm{~g}$ per tray seed rate. In Boro season, the seedling age should be within 25 - 30 days in the tray-growing seedling to reduce the seedling mortality. The study's findings could be widely disseminated among farmers to improve the quality of mat type seedlings for better mechanical rice transplanter performance, which would result in higher rice yields. However, these findings may be variety specific, and further research is required to validate the findings for other, commonly used varieties in these areas.

\section{Acknowledgements}

The authors acknowledge Dr. Md. Adil Badshah, PSO, BRRI for providing support to set up the experiment.

\section{Funding Statement}

This study was conducted under the funding support of "Strengthening Farm Machinery Research Activity for Mechanized Rice Cultivation” project, Bangladesh Rice Research Institute, Gazipur.

\section{Author's Contribution}

NY Shaikh, MA Alam and AKMS Islam generated idea; MA Alam and NY Shaikh coordinated the experiment/research/project; NY Shaikh, MA Alam and AKMS Islam developed methodology; NY Shaikh, M Kamruzzaman and AKMS Islam provided scientific insights; MA Alam gathered data; M Kamruzzaman and MAA Mamun carried out analysis and synthesis; NY Shaikh and M Kamruzzaman did the writings all versions of the manuscript; AKMS Islam, NY Shaikh, M Kamruzzaman, MA Alam and MAA Mamun performed critical review and editing; all authors read and approved the final manuscript.

\section{Availability of Data and Material}

Data used in this study are available from the first author upon request (milonbrri@gmail.com).

\section{Ethics Approval}

Not applicable.

\section{Consent to Participate}

Not applicable.

\section{Consent for Publication}

Not Applicable. 


\section{Conflicts of Interest}

The authors declare no conflicts of interest regarding the publication of this paper.

\section{References}

[1] Kumar, V., Singh, S., Kumar, R.M., Sharma, S., Tripathi, R., Nayak, A.K. and Ladha, J.K. (2017) Growing Rice in Eastern India: New Paradigms of Risk Reduction and Improving Productivity. Academic Press, Cambridge, 221-258.

https://doi.org/10.1016/B978-0-12-805374-4.00008-7

[2] Hossain, M.F., Salam, M.A., Uddin, M.R., Pervez, Z. and Sarkar, M.A.R. (2002) A Comparative Study of Direct Seeding versus Transplanting Method on the Yield of Aus Rice. Journal of Agronomy, 1, 86-88. https://doi.org/10.3923/ja.2002.86.88

[3] Manjunatha, M.V., Masthana, R.B.G., Shashidhar, S.D. and Joshi, V.R. (2009) Studies on the Performance of Self-Propelled Rice Transplanter and Its Effect on Crop Yield. Karnataka Journal of Agricultural Sciences, 22, 385-387.

[4] Dixit, A., Khurana, R., Jaskarn, S. and Gurusahib, S. (2007) Comparative Performance of Different Paddy Transplanters Developed in India-A Review. Agricultural Review, 28, 262-269. https://doi.org/10.4103/0970-2113.44201

[5] Islam, A.K.M.S. (2018) Rice Mechanization in Bangladesh. Publication Number 260. Bangladesh Rice Research Institute, Gazipur, 150 p.

[6] Islam, A.K.M.S., Rahman, M.A., Rahman, A.K.M.L., Islam, M.T. and Rahman, M.I. (2016) Techno-Economic Performance of 4-Row Self-Propelled Mechanical Rice Transplanter at Farmer's Field in Bangladesh. Progressive Agriculture, 27, 369-382. https://doi.org/10.3329/pa.v27i3.30834

[7] Zhang, W.X., Zhu, D.F., Lin, X.Q., Xu, Y.-C., Lin, X.J., Chen, H.Z. and Zhang, Y.P. (2007) The Effects of Different Sowing Densities and Raising Materials on Seedling Quality of Mechanical Transplanting Rice. Journal of Yangzhou University, 28, 45-48.

[8] Kobayashi, K., Takahashi, Y. and Fukuyama, T. (2009) Studies on the Seedling Raising Method in Giant-Embryo Rice Cultivar "Koshi Guruma” and Its Adaptability to Machine Transplanting. Japanese Journal of Crop Science, 78, 17-26. https://doi.org/10.1626/jcs.78.17

[9] Yao, X., Yang, W. and Ren, W. (2009) Effects Seedling Raising Methods and Sowing Rates on Machine-Transplanted Long-Age Rice Seedling. Transactions of the Chinese Society of Agricultural Engineering, 25, 152-157.

[10] Jia, X., Zhu, Q., Yang, Z., Sun, Y., Guo, X., Shi, Y. and Ma, J. (2014) Effect of Seedling Age on Yield and Population Quality of Mechanized Transplanted Hybrid Rice. Transactions of the Chinese Society of Agricultural Engineering, 30, 18-25.

[11] Liu, Q., Wu, X., Ma, J., Chen, B. and Xin, C. (2015) Effects of Delaying Transplanting on Agronomic Traits and Grain Yield of Rice under Mechanical Transplantation Pattern. PLOS ONE, 10, e0123330. https://doi.org/10.1371/journal.pone.0123330

[12] Liu, Q., Zhou, X., Li, J. and Xin, C. (2017) Effects of Seedling Age and Cultivation Density on Agronomic Characteristics and Grain Yield of Mechanically Transplanted Rice. Scientific Reports, 7, Article No. 14072. https://doi.org/10.1038/s41598-017-14672-7

[13] Zhang, Z.H., Qu, X.S., Wan, S., Chen, L.H. and Zhu, Y.G. (2005) Comparison of QTL Controlling Seedling Vigour under Different Temperature Conditions Using 
Recombinant Inbred Lines in Rice (Oryza sativa). Annals of Botany, 95, 423-429. https://doi.org/10.1093/aob/mci039

[14] Wang, D., Chen, S., Wang, Z., Ji, C., Xu, C., Zhang, X., et al. (2014) Optimizing Hill Seeding Density for High-Yielding Hybrid Rice in a Single Rice Cropping System in South China. PLoS ONE, 9, e109417. https://doi.org/10.1371/journal.pone.0109417

[15] Hu, Y., Wu, P., Zhang, H., Dai, Q., Huo, Z., Xu, K., Gao, H., Wei, H., Guo, B. and Cui, P. (2018) Comparison of Agronomic Performance between Inter-Sub-Specific Hybrid and Inbred Japonica Rice under Different Mechanical Transplanting Methods. Journal of Integrative Agriculture, 17, 806-816.

https://doi.org/10.1016/S2095-3119(17)61819-7

[16] Hossen, M.A., Hossain, M.M., Haque, M.E. and Bell, R.W. (2018) Effect of Seed Rate on Seedling Quality for Mechanical Rice Transplanting. Bangladesh Rice Journal, 22, 9-23. https://doi.org/10.3329/brj.v22i1.41834

[17] Gomez and Gomez (1984) Statistical Procedures for Agricultural Research. 2nd Edition, John Wiley and Sons, New York, 680 p.

[18] IRRI (2007) CropStat Stat for Windows. Version 7.2.2007.3, 3, IRRI, Metro Manila.

[19] Adhikari, B., Mehera, B. and Haefele, S. (2013) Impact of Rice Nursery Nutrient Management, Seeding Density and Seedling Age on Yield and Yield Attributes. American Journal of Plant Sciences, 4, 146-155. https://doi.org/10.4236/ajps.2013.412A3017

[20] Hamid, A., Ullah, M., Haque, M., Mollah, H.M. and Rahman, M. (2015) Improving Grain Yield of Indigenous Rice in Tidal Floodplain of Southern Bangladesh: Effect of Seedling Age and Transplanting Method. Agricultural Sciences, 6, 1538-1546. https://doi.org/10.4236/as.2015.612147

[21] Runsick, S. and Wilson, C.E. (2009) Agriculture and Natural Resources, University of Arkansas Division of Agriculture. FSA2157-PD-5-09Na.

[22] Hisashi, K., Shiratsuchi, H. and Ogura, A. (2004) Effect of Seeding Density on the Growth and Quality of Rice Seedlings in the Long-Mat Seedling Culture System. Poster Presentation in the 4th International Crop Science Congress, Brisbane, 26 September-1 October 2004. http://www.cropscience.org.au/icsc2004/

[23] Pathania, R., Shekhar, J., Rana, S.S. and Sharma, S. (2016) Evaluation of Seeding Rates of Rice Nursery on Seedling Vigour and Its Effect on Crop Productivity under System of Rice Intensification. Journal of Applied and Natural Science, 8, 2224-2230. https://doi.org/10.31018/jans.v8i4.1116

[24] Shankar, P.R., Bharti, P., Dhar, A. and Mathys, C. (2011) Operation Manual for Mechanical Transplanting of Rice. The Cereal Systems Initiative for South Asia. https://csisa.org/wp-content/uploads/sites/2/2014/06/Operational-Manual-for-Mec hanical-Transplanting-of-Rice.pdf

[25] Shahed, A.B.M., Hossen, M.A., Al Mamun, M.R., Tamanna, T.A. and Mizanur, M. (2020). Impact of Organic Substance on Growth Attributes of Mat Type Rice Seedlings in the Trays for Machine Transplanting. Journal of Science, Technology and Environment Informatics, 10, 694-708. https://doi.org/10.18801/jstei.100120.70 